\title{
Doença de Still do Adulto: Diagnóstico e Evolução(*)
}

\section{Adult-Onset Still Disease: Diagnosis and Evolution}

\author{
Simone Appenzeller ${ }^{(1)}$, Gláucio W. Castro ${ }^{(2)}$, Lílian T. L. Costallat ${ }^{(3)}$, Adil M. Samara ${ }^{(4)}$ e Manoel B. Bértolo(5)
}

\section{RESUMO}

Objetivo: determinar as manifestações clínicas ao diagnóstico e durante a evolução de pacientes com doença de Still do adulto em um hospital universitário terciário. Métodos: foram identificados 13 pacientes com a doença no Ambulatório de Artrites do HC-UNICAMP, estudados retrospectivamente, com atenção aos sintomas no momento do diagnóstico, à evolução do quadro articular e à medicação utilizada. Resultados: a prevalência da doença foi de 4,3\%. A média de idade foi de 30,8 anos com predomínio masculino (54,2\%). Todos apresentaram sintomas constitucionais, febre e exantema cutâneo ao diagnóstico. Comprometimento hepático em 100\%, com hepatomegalia em 11 (84,65\%), esplenomegalia em 4 $(30,7 \%)$, aumento de enzimas hepáticas em $6(46,1 \%)$ e hipergamaglobulinemia em 10 (76,9\%) dos pacientes. Envolvimento cardíaco em $2(15,4 \%)$ e pleurite em $1(7,7 \%)$ paciente. Hematúria foi constatada em 4 (30,7\%) casos. A manifestação articular inicial foi predominantemente poliarticular em $8(66,5 \%)$. Todos os pacientes apresentaram leucocitose ao diagnóstico, com predomínio de neutrófilos, ocorrendo linfocitose em 7 (53,8\%). Ferritina elevada em $9(69,2 \%)$ pacientes e, após a resolução do quadro, ocorreu normalização em todos. Quanto ao tratamento, todos utilizaram antiinflamatórios não-hormonais e doses baixas de corticosteróides; 7 $(69,2 \%)$ precisaram usar metotrexato. Doença monocíclica em somente $4(30,7 \%)$ pacientes, predominando doença recorrente. Bloqueio articular em 53,8\% dos pacientes, predominantemente em punhos. Conclusões: embora rara, a doença de Still do adulto deve ser sempre considerada em pacientes com envolvimento sistêmico e poliartrite, após exclusão de outras doenças, principalmente doenças infecciosas e neoplásicas. O curso da doença de Still do adulto é geralmente crônico e a principal seqüela observada neste estudo foi o bloqueio de punhos, em razão de anquilose óssea.

\begin{abstract}
Objective: To determine the clinical manifestations at disease onset and during follow-up of patients with Adult-Onset Still Disease (AOSD) in a tertiary university hospital in Brazil. Methods: Thirteen cases of AOSD were identified in the Arthritis Outpatients Unit - Unicamp. Their clinical records were reviewed retrospectively in order to determine clinical manifestations regarding disease onset, follow-up and prescription. Results: The prevalence of AOSD was $4.3 \%$. The mean age of disease onset was 30.8 years old with a slight prevalence of men (54.2\%). Constitutional symptoms, fever and cutaneous rash were observed in all cases. Hepatic involvement was observed in 11 patients, splenomegaly in 4, hematuria in 4, cardiac involvement in 2 and pleuritis in 2. Poliarticular involvement was observed more frequently, and $50 \%$ of them presented carpal ankylosis after 3 years of followup. Ferritine was elevated in 9 of 13 patients during active disease. All patients used oral non-steroidal anti-inflammatory drugs, steroids and 7 patients needed methotrexate. Conclusions: Although AOSD is a rare multisystemic rheumatic disorder, it should always be considered in febrile cases with poliarthritis. Neoplasia and infection should always be excluded. Normally it is characterized by a chronic course and carpal ankylosis as the main disabling feature.
\end{abstract}

Keywords: adult-onset Still disease, diagnosis, prognosis.

Palavras-chave: doença de Still do adulto, diagnóstico, prognóstico.

\footnotetext{
Trabalho realizado com auxílio parcial dos Fundos Remanescentes da Sociedade Brasileira de Reumatologia. Recebido em 23/05/03. Aprovado, após revisão, em 20/10/03

1. Pós-Graduanda do Departamento de Clínica Médica da UNICAMP.

2. Ex-Residente de Reumatologia da UNICAMP.

3. Professora Titular de Reumatologia da UNICAMP.

4. Professor Titular de Reumatologia e Chefe da Disciplina de Reumatologia da UNICAMP.

5. Professor Assistente de Reumatologia de UNICAMP.
}

Endereşo para correspondência: Simone Appenzeller. Departamento de Clínica Médica da Faculdade de Ciências Médicas da UNICAMP, CEP 13081-970, Campinas, SP. 


\section{INTRODUÇÃO}

A doença de Still do adulto é uma patologia inflamatória sistêmica rara, com apresentação clínica heterogênea ${ }^{(1-3)}$. Caracteriza-se por um quadro importante de sintomas constitucionais e poliartrite, podendo ser um episódio único ou recorrente. Não existem testes diagnósticos, nem achado histopatológico patognomônico, sendo, portanto, um diagnóstico de exclusão ${ }^{(2,3)}$.

O amplo espectro de apresentação dificulta o seu diagnóstico e faz com que este seja feito, muitas vezes, somente durante a evolução do quadro ${ }^{(2)}$.

O tratamento se assemelha ao da artrite reumatóide e drogas modificadoras de doença (DMARD) devem ser introduzidas precocemente, evitando assim deformidades articulares ${ }^{(1-3)}$.

O objetivo deste trabalho foi avaliar as apresentações clínicas e a evolução de pacientes com doença de Still do adulto acompanhados no Serviço de Reumatologia da UNICAMP.

\section{PACIENTES E MÉTODOS}

Foram diagnosticados 13 pacientes com doença de Still do adulto, entre 1990 e 2001, no Ambulatório de Artrites do HC-UNICAMP. Os prontuários foram revistos retrospectivamente e dados referentes a sintomatologia inicial, diagnóstico diferencial, tratamento e evolução foram inseridos em planilhas eletrônicas.

O diagnóstico da doença de Still do adulto baseou-se nos critérios de $\mathrm{Cush}^{(4)}$. As seguintes variáveis foram analisadas: freqüência de dor de garganta antes do quadro inicial, presença de febre (acima de $38^{\circ} \mathrm{C}$ ), adinamia, mialgia, artrite, fadiga, anorexia, náuseas e perda de peso. O padrão da febre, assim como exantema cutâneo associado aos picos febris, foi investigado. $\mathrm{O}$ padrão de artrite e a eventual evolução para deformidades articulares também foram analisados. A doença foi classificada como monocíclica quando somente um episódio de artrite com resolução completa foi identificado ou como recorrente quando mais de um episódio de artrite foi observado durante o seguimento. A doença foi considerada crônica quando apresentava um surto único com mais de seis meses de duração.

Dados referentes ao comprometimento hepático (hepatomegalia, aumento de enzimas hepáticas, hipoalbuminemia, hipergamaglobulinemia), à esplenomegalia e ao comprometimento renal (hematúria, leucocitúria) foram obtidos de todos. Hemograma completo, fator reumatóide, fator antinúcleo e ferritina sérica foram analisados em todos os pacientes.
Doenças infecciosas, imunodeficiências adquiridas, neoplasias e outras doenças reumatológicas foram descartadas em todos os casos.

O critério de introdução de uma droga modificadora de doença (DMARD) baseou-se na dose de corticosteróides necessária para controlar a doença, ou seja, quando superior a $10 \mathrm{mg} /$ dia. A primeira droga de escolha foi metotrexato, desde que não houvesse contra-indicações para o seu uso. $\mathrm{O}$ uso do metotrexato foi monitorado mensalmente com hemograma e função hepática e hepatotoxicidade pela droga foi considerada quando houvesse aumento de enzimas hepáticas superior a duas vezes o valor de normalidade após a introdução da droga. Outras drogas utilizadas foram o difosfato de cloroquina e a sulfassalazina.

As radiografias iniciais e de evolução de coluna cervical, punhos e região dos tarsos foram reanalisadas para determinar a prevalência de anquilose óssea nessa população.

\section{RESULTADOS}

No Ambulatório de Artrites do HC-UNICAMP, a doença de Still do adulto foi diagnosticada em 13 pacientes. A média de idade foi de 30,8 anos, com leve predomínio para o sexo masculino $(54,2 \%)$. Os caucasóides foram acometidos em maior freqüência $(92,3 \%)$. As características demográficas dos pacientes estão resumidas na Tabela 1.

TABELA 1

Doença de STILl do adulto:

CARACTERÍSTICAS DEMOGRÁFICAS

\begin{tabular}{lc}
\hline Características demográficas & Freqüência \\
\hline Sexo masculino/feminino & $1,6 / 1$ \\
Média de idade (anos \pm DP) & $30,8(12,2)$ \\
Caucasóide & $92,3 \%$ \\
Tempo de doença (anos \pm DP) & $6,3(1,8)$ \\
Tempo de acompanhamento (anos \pm DP) & $4,8(1,2)$ \\
\hline
\end{tabular}

O diagnóstico foi feito, em média, após 6,9 meses de doença. Sintomas constitucionais foram observados em todos, sendo o motivo para a procura de auxilio médico em $69,2 \%$ dos casos.

Dor de garganta anterior aos sintomas foi referida por 9 pacientes $(69,2 \%)$, ocorrendo entre uma e três semanas antes do quadro inicial. Febre e exantema cutâneo evanescente foram observados em todos. A febre, com temperaturas superiores a $38^{\circ} \mathrm{C}$, apresentava padrão vespertino com um a dois picos diários e resposta parcial a antitérmicos. 
O exantema cutâneo evanescente e pruriginoso piorava com a febre e localizava-se preferentemente em membros superiores, tronco e pescoço. Mialgia generalizada foi referida por $7(53,8 \%)$ e artralgia migratória por $11(84,6 \%)$ pacientes. Fadiga, com piora durante os episódios de febre, foi referida por $8(61,5 \%)$ e anorexia por $5(3,5 \%)$ pacientes. Perda de peso, média de seis quilos, foi relatada por 6 $(46,1 \%)$ pacientes, antes do diagnóstico.

Os motivos dos encaminhados ao Ambulatório de Reumatologia foram: febre de origem indeterminada, leucocitose, hepatoesplenomegalia febril e diagnóstico prévio de artrite reumatóide. $\mathrm{Na}$ maioria dos casos, os pacientes haviam sido previamente investigados por hematologistas e infectologistas.

Durante o exame físico na primeira consulta nesse serviço, artrite foi observada em todos, sendo poliarticular em 8 (61,5\%), acometendo especialmente joelhos, punhos, tarso, tornozelos e interfalangeanas proximais. Não houve referências ao acometimento de coxofemorais e as interfalangeanas foram acometidas em 2 pacientes. Hepatomegalia foi diagnosticada em $11(84,6 \%)$ e esplenomegalia em 4 (30,7\%). As manifestações clínicas iniciais estão resumidas na Tabela 2.

Leucocitose, em média de 20.000 (normal até 8.000), com predomínio de neutrófilos, foi observada em todos. Linfocitose associada foi constatada em 53,8\% dos casos. Aumento assintomático de enzimas hepáticas foi notado em $6(46,1 \%)$ e hipergamaglobulinemia em 11 (84,6\%) pacientes. Nenhum deles tinha fator reumatóide ou fator antinúcleo (FAN) positivo. Ferritina elevada foi observada em 9 (69,2\%), com valor médio de $1.100 \mathrm{mg} / \mathrm{dL}$ (normal $235 \mathrm{mg} / \mathrm{dL}$ ). Os

\section{TABELA 2}

DOENCA DE STILL DO ADULTO: MANIFESTACÕES CLÍNICAS INICIAIS

\begin{tabular}{lc}
\hline $\begin{array}{l}\text { Manifestações clínicas } \\
\text { ao diagnóstico }\end{array}$ & $\begin{array}{c}\text { Número de } \\
\text { pacientes }(\%)\end{array}$ \\
\hline Exantema cutâneo & $13(100)$ \\
Febre & $13(100)$ \\
\hline Artrite & $13(100)$ \\
\hline Hepatomegalia & $11(84,6)$ \\
\hline Dor de garganta antes do início do quadro sistêmico & $9(69,2)$ \\
Fadiga & $8(61,5)$ \\
Linfadenopatia & $7(53,8)$ \\
Mialgia & $7(53,8)$ \\
Dor abdominal & $6(46,2)$ \\
\hline Perda de peso importante & $6(46,2)$ \\
Esplenomegalia & $4(30,8)$ \\
\hline
\end{tabular}

níveis de ferritina correlacionaram-se diretamente com a atividade da doença, diminuindo com o tratamento efetivo. Além disso, em todos os casos em que a remissão foi atingida, os níveis de ferritina se normalizaram.

Comprometimento renal, caracterizado por hematúria nãodismórfica e leucocitúria estéril, foi diagnosticado em 4 (30,7\%) pacientes, normalizando-se estes achados em todos os pacientes com o tratamento efetuado. A hematúria não se correlacionou ao uso de antiinflamatórios ( $\mathrm{p}>0,05)$, nem ao uso de qualquer outra medicação. A presença de litíase renal foi afastada em todos os casos com ultra-sonografia abdominal.

Envolvimento cardíaco, na forma de pericardite, foi observado em 2 (3,8\%) pacientes, sendo todos os casos caracterizados como leves, sem risco de tamponamento e, portanto, sem necessidade de uso de corticosteróides em altas doses. Pleurite foi identificada em 1 (7,7\%) paciente, tratada com corticosteróides na dose de $1 \mathrm{mg} / \mathrm{kg} / \mathrm{dia}$, com resolução completa.

Quanto ao tratamento, todos os pacientes utilizaram antiinflamatórios não-hormonais e doses baixas de corticosteróides. Sete $(53,8 \%)$ pacientes precisaram usar DMARDs para controlar as manifestações articulares, sendo o metotrexato a droga de escolha em seis pacientes. Hepatotoxicidade secundária ao uso do metotrexato foi considerada quando ocorreu aumento das enzimas hepáticas após a introdução da droga. Sulfassalazina foi prescrita para um paciente, devido à contra-indicação para o uso de metotrexato. Com o tratamento instituído, os sintomas constitucionais, os níveis séricos de ferritina, a anemia e a leucocitose regrediram progressivamente até a normalização em todos os pacientes.

Doença monocíclica foi observada em 4 (30,7\%), doença crônica em 2 (15,3\%), predominando doença recorrente neste estudo em 7 (53,8\%) pacientes.

Osteopenia periarticular foi observada em 11 (84,6\%) e erosões ósseas em $5(38,5 \%)$ pacientes. As interfalangeanas distais foram acometidas em 2 (15,4\%). Bloqueio articular, predominando em punhos, foi constatado em 7 (53,8\%) dos pacientes. Os demais pacientes não apresentaram seqüela articular. Até o final deste estudo, 6 (46,1\%) pacientes estavam sem medicação e os demais controlados com doses estáveis de DMARDs e corticosteróides.

\section{DISCUSSÃO}

Doença de Still do adulto é uma doença reumatológica rara caracterizada por febre alta, exantema cutâneo e artrite ${ }^{(1-}$ 3). A etiologia ainda é desconhecida, mas muitas 
características clínicas são semelhantes àquelas observadas durante infecções virais autolimitadas, mas alguns autores ${ }^{(1,2)}$ demonstraram a persistência de antígenos virais, principalmente da rubéola, nestes pacientes.A doença de Still do adulto já foi observada em quase todos os países e em todas as raças. No entanto, existem poucos estudos com mais de 10 pacientes. Estas séries sugerem que a doença de Still é rara e que centros de referência recebam um a três casos novos por ano ${ }^{(1-7)}$. Em grandes séries que analisaram pacientes com febre de origem indeterminada, a doença de Still do adulto foi a doença reumatológica mais freqüentemente diagnosticada, entre 5\% e 9\% dos $\operatorname{casos}^{(2,3)}$.

A doença acomete tipicamente adultos jovens, ocorrendo antes dos 35 anos em 76\% dos casos, dado confirmado nesta casuística. Não foi observada predominância de sexo no presente estudo, assim como por outros autores ${ }^{(1,3,6,8)}$.

A doença de Still do adulto é caracterizada por um pródromo de dor de garganta não-exudativa e não-responsiva à antibioticoterapia e outros sintomas constitucionais $^{(1-7,9)}$. Este sintoma foi referido por $69,2 \%$ dos pacientes neste trabalho e todos referiam sintomas constitucionais importantes como mal-estar, mialgia e artralgia. A perda de peso é relatada em $50 \%$ a $60 \%$ dos pacientes ${ }^{(1-7)}$, podendo ser dramática e rápida e correlacionando-se à atividade inflamatória, medida por queda da hemoglobina e albumina ${ }^{(2)}$. Neste trabalho, a perda de peso foi referida por seis pacientes, ocorrendo em média uma perda de seis quilos.

O padrão de febre mais comumente descrito na doença de Still do adulto é o de picos febris, manifestando-se uma a duas vezes por dia e podendo chegar a $40^{\circ} \mathrm{C}$ em cerca de $60 \%$ dos $\operatorname{casos}^{(2,3)}$. Uma das características importantes desta febre é a ocorrência dos picos febris sempre no mesmo horário, principalmente à noite, acompanhados de sudorese profusa. Febre foi observada em todos os pacientes desta casuística, ocorrendo principalmente dois picos diários.

O exantema cutâneo foi relatado em mais de $92 \%$ dos pacientes, caracterizado por ser evanescente, cor de salmão, aparecendo freqüentemente durante picos febris e durando algumas horas. A recorrência geralmente se dá em outro local ${ }^{(1-3)}$. O exantema cutâneo foi observado em todos os pacientes desta casuística, ocorrendo principalmente nas extremidades e no tronco. O comprometimento da face é muito raro ${ }^{(2)}$ e neste estudo não foi observado. As manifestações cutâneas tendem a ser mais importantes no início da doença, melhorando com a evolução. Estudos anteriores que analisaram biópsias de pele demonstraram padrões de imunofluorescência negativos ${ }^{(2)}$. A biópsia de pele não foi realizada em nenhum paciente desta casuística.
Artrite ocorre em torno de $93 \%$ dos casos e geralmente é a última manifestação a aparecer ${ }^{(1-4)}$. No início há predomínio de um quadro de artralgia, mialgia, rigidez matinal e menos freqüentemente de sinovite ${ }^{(2,3)}$. A artrite pode ser oligoarticular, mas, na maioria das vezes, ela é aditiva, acometendo grandes e pequenas articulaçõe ${ }^{s(2)}$. Neste estudo, a poliartrite foi mais freqüente, ocorrendo em 100\% dos casos. As articulações mais comumente envolvidas em nossa casuística foram joelhos, punhos, tornozelos, cotovelos, ombros, interfalangeanas proximais e coluna cervical. A doença de Still do adulto está associada à anquilose de carpo ou metacarpo em $50 \%$ dos casos $^{(1-3)}$, e neste trabalho a anquilose de carpo foi observada em 53,6\%.

Linfadenomegalia, esplenomegalia e hepatomegalia são muito freqüentes no início da doença, ocorrendo, respectivamente, em $65 \%, 42 \%$ e $40 \%$ dos casos e refletem a infiltração tecidual por células inflamatórias e aumento da atividade imunológica no sistema reticuloendotelial ${ }^{(1-5)}$. No presente estudo, a freqüência destas manifestações foi similar à previamente descrita, com linfadenomegalia ocorrendo em 38,5\%, esplenomegalia em 30,7\% e hepatomegalia em $84,6 \%$ dos casos. Após o controle adequado da doença houve desaparecimento da linfoadenopatia e regressão da hepatoesplenomegalia em todos os casos.

Cerca de 70\% dos pacientes desenvolvem algum grau de disfunção hepática, demonstrado por aumento de enzimas hepáticas ${ }^{(1-3)}$, o que ocorreu em $46,1 \%$ neste presente estudo. Biópsia hepática tende a ser não conclusiva, evidenciando infiltrado mononuclear periportal e hiperplasia de células de $\operatorname{Kupffer}^{(2,3)}$, e não foi realizada neste trabalho.

Pericardite ocorreu em duas pacientes e pleurite em uma, com boa resposta à corticoterapia e com freqüência muito inferior à de outros trabalhos, que reportaram, respectivamente, $40 \%$ e $30 \%^{(2,4,10)}$. Talvez a avaliação rotineira com ecocardiografia, principalmente na avaliação de pericardite, mesmo nos casos assintomáticos possa modificar estes resultados. Pneumonite, que não foi observada nesta casuística, ocorreu em torno de $20 \%$ dos casos em outros relatos $^{(2,4)}$, caracterizada por infiltrado alveolar e intersticial, bilateral, em radiografias de tórax. Dor abdominal, encontrada em $46,2 \%$ neste estudo, é descrita em $30 \%$ em outras séries ${ }^{(1,3)}$. Sua etiologia varia, podendo ser secundária à peritonite, linfadenite mesentérica, distensão hepática ou esplênica ou ainda secundária ao íleo adinâmico ou obstrução intestinal ${ }^{(2)}$.

Comprometimento renal não é freqüente na doença de Still do adulto, podendo ocorrer proteinúria durante os 
quadros febris ou hematúria não-dismórfica ${ }^{(2)}$. Neste estudo, a hematúria foi observada em 4 (7,7\%) pacientes, com evolução favorável em todos os casos.

Outras manifestações que podem ocorrer na doença de Still do adulto como perda auditiva sensório-motora, meningite asséptica ${ }^{(11)}$, meningoencefalite, pseudotumor orbital, coagulação intravascular disseminada, síndrome hemofagocítica e ceratoconjuntivite "sicca" não foram observadas neste estudo ${ }^{(1-3)}$.

Apesar da doença de Still do adulto apresentar várias características de uma doença inflamatória sistêmica, ela não apresenta nem fator reumatóide nem FAN positivos ${ }^{(1-3)}$. A maioria dos pacientes, como observado neste trabalho, apresenta leucocitose neutrofílica com leucócitos em torno de 12.500 a 40.000 células por $\mathrm{mm}^{3}$. Leucopenia ou leucocitose extrema são raras e devem alertar para diagnósticos como leucoses, linfomas ou síndrome hemofagocítica. A elevação dos reagentes de fase aguda é freqüente, incluindo VHS, PCR, amilóide sérico A, complemento, haptoglobina e ferritina sérica ${ }^{(1-7)}$. A ferritina sérica, por ser também um reagente de fase aguda, está moderadamente elevada na doença de Still do adulto, porém elevações extremas (acima de 40.000) merecem diagnósticos diferenciais com hemocromatose, neoplasias, pancreatites, septicemia ou outras doenças inflamatórias como artrite reumatóide ou lúpus eritematoso sistêmico ${ }^{(1-3,11,12)}$.

O diagnóstico da doença de Still do adulto é necessariamente um diagnóstico de exclusão, em virtude do amplo espectro de diagnósticos diferenciais, principalmente das doenças que causam febre de origem indeterminada ${ }^{(2)}$. A necessidade de afastar doenças infecciosas, neoplásicas e outras doenças reumatológicas muitas vezes retarda o diagnóstico ${ }^{(1-4)}$. Além disso, as manifestações constitucionais normalmente são importantes, necessitando de internação. A leucocitose marcante que acompanha o quadro clínico torna imperativo o afastamento de leucoses e freqüentemente um mielograma torna-se indispensável ${ }^{(1-4)}$. Porém,

\section{REFERÊNCIAS}

1. Al-Arfaj AS, Al-Saleh S. Adult-Onset Still's disease in Saudi Arabia. Clin Rheumatol 2001;20(3):197-200.

2. Cush JJ. Adult-onset Still's disease. Bull Rheum Dis 2000;49(6):1-4.

3. Garcia-Porrua C, Gonzalez-Gay MA, Crespo F, Gonzalez-Juanatey C. Adult onset Still's disease in Catalonia, Spain. J Rheumatol 2000;27(1):280-1.

4. Cousin F, Grezard P, Roth B, Balme B, Gregoire-Bardel M, Perrot H. Kikuchi's disease associated with Still's disease. Int J Dermatol 1999;38(6):464-7. o achado de leucocitose reacional geralmente direciona o diagnóstico para doença de Still do adulto.

O tratamento recomendado é semelhante ao da artrite reumatóide ${ }^{(1-3,13)}$. Corticosteróides em doses elevadas são usados somente para pericardite com risco de tamponamento, pleurite grave e para a síndrome hemofagocítica. A indometacina é o antiinflamatório de escolha, com boa ação também contra a febre ${ }^{(2,3)}$. Corticosteróides orais em baixas doses e DMARDs são indicados para as manifestações $\operatorname{articulares}^{(14-16)}$. Não obstante a disfunção hepática ser esperada em pacientes com doença de Still, o metotrexato pode ser empregado, desde que o paciente seja monitorado com hemograma e função hepática. Metotrexato é a droga de escolha ${ }^{(15,16)}$, porém, na presença de disfunção hepática grave ou fibrose pulmonar, o difosfato de cloroquina e a sulfassalazina podem ser utilizados ${ }^{(2,14-16)}$.

As manifestações extra-articulares como leucocitose, anemia, linfonodomegalia e hepatomegalia, entre outras, melhoram com o tratamento efetivo da doença ${ }^{(2,3)}$. O uso de DMARDs está também indicado como poupador de corticosteróides, evitando o efeito deletério desta medicação a longo prazo ${ }^{(14-16)}$.

O prognóstico da doença de Still do adulto é bom. Em torno de $20 \%$ dos pacientes apresentam uma doença monocíclica, com duração de 4 a 12 meses. A maioria dos pacientes, como observado neste estudo, apresenta uma doença sistêmica recorrente. O bloqueio articular dos punhos, presente em elevado número de pacientes neste trabalho, é uma complicação que deve ser monitorada cuidadosamente. Os casos de óbito relatados são decorrentes de efeitos colaterais das medicações, de co-morbidades associadas ou de acidentes ${ }^{(17)}$.

A doença de Still do adulto, nos casos de febre de origem indeterminada, deve ser sempre considerada na abordagem do diagnóstico diferencial. Deve-se enfatizar que este diagnóstico é sempre de exclusão, sendo necessária a investigação de doenças infeciosas e neoplásicas, entre outras.

5. Schachna L, Littlejohn GO. Adult-onset Still's disease: a concise review of clues to an important rare syndrome. Aust N Z J Med 1999;29(1):98-9.

6. Jaime MAI, Baptista R, Azevedo M, et al. Doença de Still do adulto: estudo de 25 casos. Rev Bras Reumatol 1998;38:285-90.

7. Rêgo J, Ximenes AC, Silva NA, et al. Doença de Still no adulto. Rev Bras Reumatol 1991;31(1):1-4

8. Cheema GS, Quismorio FP Jr. Pulmonary involvement in adultonset Still's disease. Curr Opin Pulm Med 1999;5(5):305-9.

9. Nguyen KH, Weisman $\mathrm{MH}$. Severe sore throat as a presenting symptom of adult onset Still's disease: a case series and review of the literature. J Rheumatol 24(3):592-7. 
10. Moder KG, Miller TD, Allen GL. Cardiac tamponade: an unusual feature of adult onset Still's disease. J Rheumatol 22(1):180-2.

11. Marie I, Levesque H, Perraudin N, Cailleux N, Lecomte F, Courtois $\mathrm{H}$. Aseptic meningitis and cranial nerve palsy revealing adult-onset Still's disease. Clin Infect Dis 1999;29(1):220-1.

12. Schiller D, Mittermayer H. Hyperferritinemia as a marker of Still's disease. Clin Infect Dis1998;26(2):534-5.

13. Akritidis N, Giannakakis Y, Sakkas L. Very high serum ferritin levels in adult-onset Still's disease. Br J Rheumatol 1997;36(5):608-9.

14. Fujii T, Akizuki M, Kameda H, Matsumura M, Hirakata M, Yoshida T, Shinozawa T, Mimori T. Methotrexate treatment in patients with adult onset Still's disease-retrospective study of 13 Japanese cases. Ann Rheum Dis 1997;56(2):144-8.

15. Aydinting AO, D'Cruz D, Cevera R, et al. Low dose methotrexate in treatment of AOSD. J Rheumatol 1992;19:431-5.

16. Faufie B, Borget C, Rozenberg S, et al. Corticosteroid sparing effect of low dose MTX treatment in AOSD. J Rheumatol 1999; 26:373-8.

17. Sampalis JS, Esdaile JM, Medsger TA Jr, et al. A controlled study of the long-term prognosis of adult Still's disease. Am J Med 1995; 98(4):384-8. 